\title{
LINEAMENTOS EM IMAGENS DE SENSORES REMOTOS E SEU SIGNIFICADO ESTRUTURAL NOS TERRENOS GRANITO-GREENSTONE BELT DE CRIXÁS (GO)
}

\author{
CLÁUDIA LIMA DE QUEIROZ ${ }^{1,2}$, PAULO ROBERTO MENESES ${ }^{3}$ \& HARDY JOST ${ }^{4}$
}

\begin{abstract}
REMOTE SENSING IMAGE LINEAMENTS AND THEIR STRUCTURAL SIGNIFICANCE IN THE CRIXÁS GRANITEGREENSTONE BELT TERRANE (GO) This paper presents the results of the interpretation of lineaments from three different remote sensing images (SLAR-GEMS 1000, TM-LANDSAT and SAR-JERS-1) applied to the Crixás granite-greenstone belt terrane, Central Brazil. Two main lineament systems are identified. One is a $N 30^{\circ} \mathrm{W}-\mathrm{N} 30^{\circ} \mathrm{E}$ pair intepreted as related to a Palaeoproterozoic deformation. The other is a $\mathrm{N} 50^{\circ} \mathrm{W}$ $\mathrm{N} 70^{\circ} \mathrm{E}$ pair that cuts the former and is interpreted as related to a Neoproterozoic deformation (Brasiliano Cycle). The images from different sensors provides a more complete observation of relief patterns and associated structures and a better framework of the regional lineament geometry, but their kinematics is only provided by data from outcrops.
\end{abstract}

Keywords: Lineaments, structural geology, images, greenstone belts, Goiás

RESUMO Este artigo apresenta os resultados da interpretação de lineamentos a partir de três diferentes imagens de sensores remotos (SLAR GEMS 1000 , TM-LANDSAT 5 e SAR-JERS-1) aplicada aos terrenos granito-reenstone belt de Crixás, Goiás. Dois pares principais de sistemas de lineamentos foram identificados. Um compreende um par $\mathrm{N} 30^{\circ} \mathrm{W}-\mathrm{N} 30^{\circ} \mathrm{E}$ e é interpretado como uma deformação paleoproterozóica e, outro, um par $\mathrm{N} 50^{\circ} \mathrm{W}-\mathrm{N} 70^{\circ} \mathrm{E}$ que corta o anterior e interpretado como uma deformação neoproterozóica. A análise de imagens de sensores diferentes propicia uma observação mais completa dos padrões de relevo e estruturas associadas e um melhor arcabouço geométrico dos lineamentos, mas cuja cinemática depende de dados de campo.

Palavras-chave: Lineamentos, geologia estrutural, imagens, greenstone belt, Goiás

INTRODUÇÃO Os terrenos granito-greenstone belt arqueanos de Crixás localizam-se na região norte-noroeste do Estado de Goiás. Os depósitos de ouro, inicialmente explorados pelos Bandeirantes, transformaram a região em importante distrito mineiro e, a partir dos meados da década de 80 passou a ser alvo de diversos estudos sobre a geoquímica, estratigrafia e geologia econômica, mas investigações detalhadas sobre geologia estrutural iniciaram apenas na década de 90 .

Fisiograficamente a área se localiza no limite entre o Planalto do Alto Tocantins - Paranaíba e a Depressão do Araguaia. Em geral, os terrenos arqueanos se sobressaem na paisagem regional, pois os greenstone belts sustentam serras em cristas paralelas, alinhadas segundo NS a NW-SE, subsidiariamente, formas tabulares e convexas (Brasil 1981) ou conformam, localmente, depressões. Por outro lado, os terrenos granito-gnáissicos definem, genericamente, depressões, localmente serras. Ambos declinam de altitude em para norte e oeste, em direção à Depressão do Araguaia.

A forma e o comportamento espacial dos elementos morfoestruturais de relevo (EMR) observáveis em imagens de sensores remotos, pelo seu caráter sinóptico, são atributos valiosos na pesquisa de grandes traços estruturais. Contudo, o entendimento da sua cinemática claramente depende de informações de campo.

A análise de EMR nos terrenos granito-greenstone belt de Crixás realizou-se antes dos trabalhos de campo, possibilitando o reconhecimento da geometria regional dos traços estruturais, antes da cinemática local. O presente trabalho mostra que o emprego de diversos tipos de sensores na análise de EMR aumenta a confiabilidade da interpretação geométrica de lineamentos de natureza e direção distintas.

GEOLOGIA LOCAL Os terrenos arqueanos da região de Crixás compreendem uma parte do Maciço de Goiás, Província Tocantins (Almeida 1967), são circundados por rochas de idade variável entre o Paleoproterozóico e o Neoproterozóico e consistem de estreitas faixas de greenstone belt emolduradas por complexos granito-gnáissicos, em estruturação de domos-e-quilhas (sensu Marshak et al. 1997). Na região de Crixás, porção setentrional dos terrenos arqueanos, os greenstone belts ocorrem em três faixas alongadas na direção aproximada NS e denominados, de oeste para leste, de Crixás, Guarinos e Pilar de Goiás (Danni \& Ribeiro 1978, Saboia 1979). Os terrenos granito-gnáissicos compreendem, no mesmo sentido, os Complexos da Anta e Caiamar, o Bloco Moquém e o Complexo Hidrolina (Jost et al. 1994 a, 1994b, Resende et al. 1998) (Fig. 1). Para melhor compreender a evolução individual de cada faixa, Jost \& Oliveira (1991) propu- seram a sua divisão nos Grupos Crixás, Guarinos e Pilar de Goiás. Apesar de respectivas complexidades internas, a estratigrafia de cada grupo contem uma sequiência metavulcânica inferior composta de metakomatiitos seguidos de métabasaltos toleiíticos e uma metassedimentar de topo, litologicamente variável entre as faixas e consistindo de proporções variadas de xistos carbonosos e metarritmitos (Crixás e Guarinos), localmente com mármores oolíticos (Crixás) e formaçōes ferríferas e manganesíferas (Guarinos), e rochas calcissilicáticas e metapelitos (Pilar de Goiás).

$\mathrm{Na}$ área estudada, os terrenos arqueanos estão parcialmente cobertos por rochas supracrustais proterozóicas (Sequêencia Morro Escuro, Sequiência Santa Terezinha e Grupo Araxá). A Sequiência Morro Escuro (Jost et al. 1989) ocorre na porção sul e consiste de formações ferríferas bandadas e mármores, subordinadamente metaconglomerados e metapelitos. A Seqüência Santa Terezinha ocorre imediatamente a norte dos terrenos arqueano e compreende metapelitos e metavulcânicas félsicas e máficas, localmente ultramáficas (Biondi 1990). O Grupo Araxá se estende ao longo de todo o limite leste, sudeste e sul e compreende quartzitos micáceos a microconglomeráticos sotopostos a espessa e monótona sucessão de metapelitos seguidos de calcixistos. As três unidades assentam sobre rochas arqueanas por meio de falhas de empurrão.

GEOLOGIA ESTRUTURAL Queiroz (2000) propôs que a evolução estrutural da porção setentrional dos terrenos arqueanos da região de Crixás envolve três eventos $\left(\mathrm{E}_{\mathrm{n}-2}\right.$ a $\left.\mathrm{E}_{\mathrm{n}}\right)$ e cinco fases de deformação $\left(D_{n-3}\right.$ a $\left.D_{n+1}\right)$. A feição estrutural mais marcante da região é a alternância, em segmentos genericamente orientados segundo NS, de complexos granito-gnáissicos e greenstone belts em padrão residual de domos-e-quilhas (Fig. 1) do tipo M (sensu Marshak et al. 1997). Dados geocronológicos U-Pb SHRIMP em zircão e titanita (Queiroz 2000) mostram que esta é a arquitetura final do Arqueano e que, mesmo com retrabalhamento no Paleoproterozóico e Neoproterozóico, é possível distinguir que as fases de deformação $D_{n-3}$ e $D_{n-2}$ são arqueanas, $D_{n-1}$ é paleoproterozóica e $D_{n}$ e $D_{n+1}$ neoproterozóicas.

Arqueano Evidências da deformação $D_{\text {for }}$ foram registradas apenas nos greenstone belts (Crixás, Guarinos e Pỉlar de Goiás) e indicam um evento de deformaç̃o e metamorfismo regionais anteriores ao soerguimento dos complexos granito-gnáissicos adjacentes. A foliação atribuída a essa fase é denominada por Queiroz (2000) de $S_{1-3} / / S_{0}=S_{1}$ Em Guarinos, Jost et al. (1995) descrevem que a intrusão do Tonali to

1. Departamento de Geologia Regional e Geotectônica, Faculdade de Geologia, Universidade do Estado do Rio de Janeiro, Rua São Francisco Xavier, 524, sala 4024, bloco A. Maracanã, Rio de Janeiro, RJ, 20.559-900, FAX: 21-587.7704. e-mail: clqueiro@uerj.br

2 - Instituto de Geociências, Universidade de Brasília. Campus Universitário Darcy Ribeiro, Asa Norte, Brasília, DF, 70.910-900.

3 - Departamento de Geologia Geral e Aplicada, Instituto de Geociências, Universidade de Brasília. Campus Universitário Darcy Ribeiro, Asa Norte, Brasília, DF, 70.910-900,FAX: 61-347.4062.e-mail: Isrunb@unb.br

4 - Departamento de Geoquímica e Recursos Minerais, Instituto de Geociências, Universidade de Brasília. Campus Universitário Darcy Ribeiro, Asa Norte, Brasília, DF, 70.910-900,FAX: 61-347.4062.e-mail: hjost@tba.com.br 


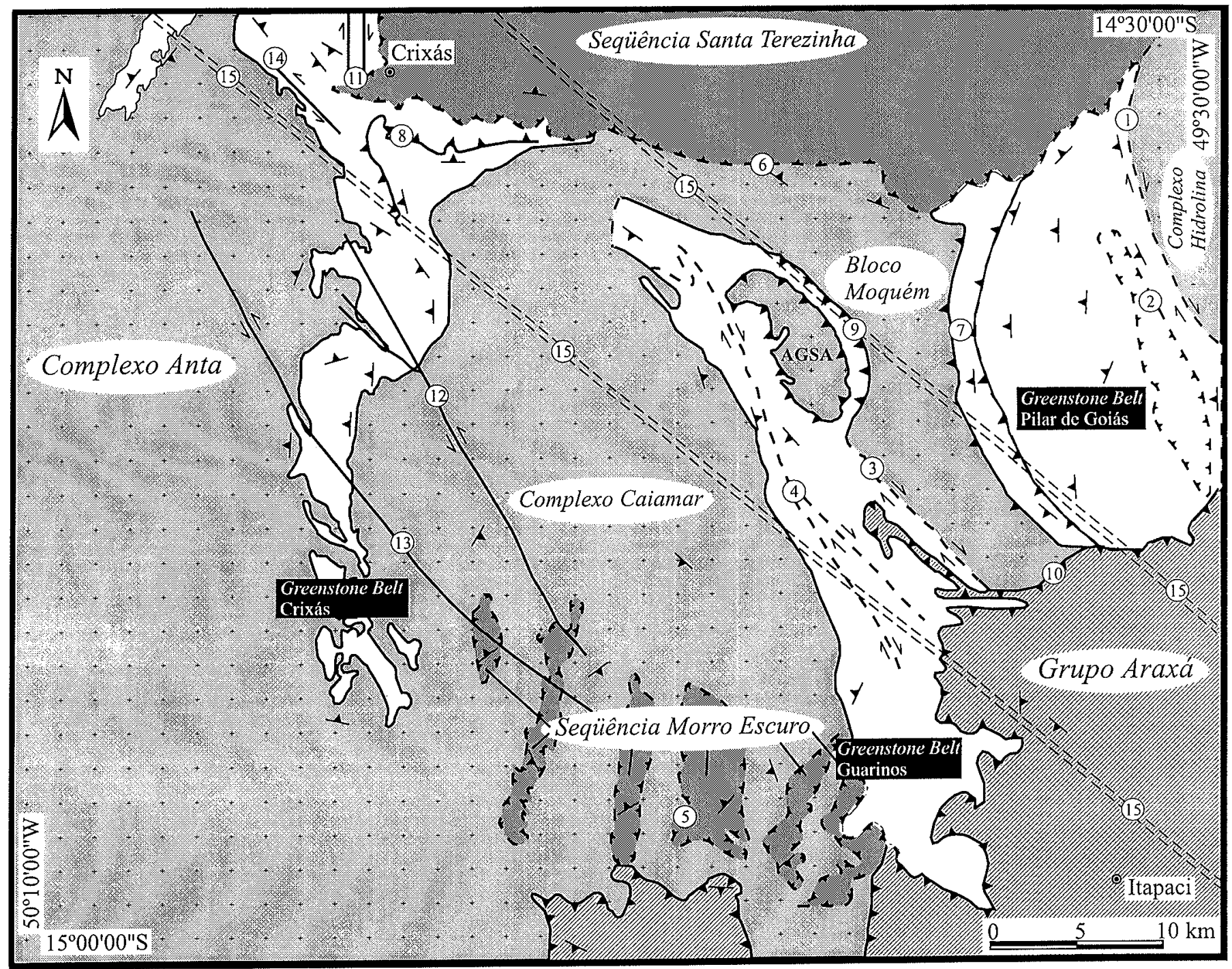

\section{TERRENOS PROTEROZÓICOS}

\section{Meso-Neoproterozóico - Grupo Araxá}

Paleoproterozóico - Seqüência Morro Escuro e Seqüência Santa Terezinha

\section{TERRENOS GRANITO-GREENSTONE BELT}

Supracrustais dos Greenstone Belts

F. Terrenos Granito-Gnáissicos

\section{AGSA - Albita Granito Santo Antônio}

\section{LEGENDA}

Foliação principal $\left(\mathrm{S}_{\mathrm{p}}\right)$

Zonas de cisalhamento reverso $\left(\mathrm{ZCR}_{\mathrm{n}-1}\right)$

Z Zonas de cisalhamento transcorrente $\left(\mathrm{ZCT}_{\mathrm{n}-1}\right)$

Zonas de cisalhamento reverso $\left(\mathrm{ZCR}_{\mathrm{n}}\right)$

Zonas de cisalhamento transcorrente $\left(\mathrm{ZCT}_{\mathrm{n}+1}\right)$

Corredor Transpressivo

Ribeirão das Antas/Rio Vermelho
1- ZC João Leite

2-Klippe calcissilicáticas

3- ZC Carroça

4- ZC Engenho Velho

5- Klippen Morro Escuro

6- Seqüência Santa Terezinha - Alóctone

Fase $D_{n+1}$

7- ZC Três Buracos

8- Cinturão de Cisalhamento de Empurrão

Córrego Geral-Meia Pataca

9- ZC do norte de Guarinos

10- Grupo Araxá - Alóctone

11- ZC Garimpo da Lavra

12- ZC Córrego Eleutério

13- ZC Ribeirão Alagado

14- Zona Mestra

15- Corredor Transpressivo Ribeirão das Antas/Rio Vermelho
Fase $\mathrm{D}_{n}$

Fase $D_{n+}$

Figura I-Mapa estrutural simplificado dos greenstone belts de Crixás, Guarinos e Pilar de Goiás (modificado de Queiroz 2000). Cartografia das zonas de cisalhamento reverso, na parte central do greenstone belt de Crixás, é simplificada de Magalhães (1991). 
Tocambira (2.842 $\pm 6 \mathrm{Ma}$, Queiroz 2000), uma das unidades do Complexo Caiamar, deformou $S_{n-3} / / S_{0}=S_{\text {, }}$, com metamorfismo de contato na fácies epidoto-anfibolito superposto ao de metamorfismo regional da fácies xisto verde. A deformaçã̃o de $\mathrm{S}_{\mathrm{n}-3} / / \mathrm{S}_{0}=\mathrm{S}_{\mathrm{p}}$ também ocorre nas proximidades do contato dos complexos da Anta e Caiamar com as rochas da faixa Crixás, ainda que de forma menos evidente que em Guarinos. Em Pilar de Goiás, o basculamento da sucessão estratigráfica para oeste é evidenciado pela variação da atitude de $S$ $/ / \mathrm{S}_{0}=\mathrm{S}_{p}$, e é atribuído ao soerguimento do Complexo Hidrolina $\left(2.785 \pm 5^{\prime} \mathrm{Ma}\right.$, Queiroz 2000). O paralelismo entre $S_{n-3}$ e $S_{0}$ indica que houve transposição generalizada de $S_{0}$ e que $S_{p-3}$ é superfície axial de dobras apertadas a isoclinais de porte regional. Conclui-se, daí, que $\mathrm{D}$ foi provavelmente de natureza reversa e que pode representar um transporte tectônico epidérmico de vergência ainda incerta.

Nos greenstone belts, $\mathrm{D}_{\mathrm{n}-2}$ resulta do soerguimento dos complexos granito-gnáissicos e, nas proximidades dos contatos entre ambos, $\mathrm{D}_{\mathrm{n}}$ é dada pela deformação de $S_{\text {en }}$ em trajetória paralela ao contato. Em Crixás, a trajetória de $S$ é, em geral, festonada, em Guarinos é linear e em Pilar de Goiás curvilínea com concavidade voltada para NE. A ascensão dos granitóides deformou $S_{p}$ em estreitas sinformes $\left(F_{n-2}\right)$ de eixo curvilíneo que acompanham o traço do contato. As sinformes são raras ao longo do contorno do greenstone belt de Crixás, mas freqüentes no de oeste de Guarinos (Jost et al. 1995). Por sua vez, a metade leste de Guarinos e a faixa de Pilar de Goiás estão basculados em homoclinais com mergulho para quadrantes de oeste, o primeiro pela ascensão do Bloco Moquém e o último pela do Complexo Hidrolina. Essas feições indicam que a deformação das supracrustais durante $\mathrm{D}_{\mathrm{n}}$ ${ }_{2}$ foi essencialmente dúctil.

A idade do metamorfismo da fase $D_{n-2}$ (Queiroz et al. 2000) foi obtida nos Gnaisses Crixás Açu (Complexo Caiamar) e situa-se entre $2.772 \pm 6 \mathrm{Ma}$ (zircão metamórfico) e $2.711 \pm 34 \mathrm{Ma}$ (titanita metamórfica).

Paleoproterozóico As estruturas resultantes da deformação paleoproterozóica estão reunidas na fase $\mathrm{D}_{\mathrm{n}-1}$ e resultaram de um importante transporte tectônico para norte. Esta fase se evidencia por feições estruturais e intrusões de albita granitos e dioritos. A freqüência e intensidade das feições estruturais e da atividade magmática desta fase crescem de oeste para leste. No extremo sul da área, se evidenciam por klippen de supracrustais arqueanas e da Sequiência Morro Escuro sobre o Complexo Caiamar (Queiroz 2000).

A família de estruturas de $D_{n-1}$ compreende lineações de estiramento e mineral $\left(\mathrm{Lm} / \mathrm{e}_{\mathrm{n}-1}\right)$, dobras $\left(\mathrm{F}_{\mathrm{n}-1}\right)$, zonas de cisalhamento transcorrente ( $\left.\mathrm{ZCT}_{n+1}\right)$ e klippen. Esta fase aparentemente não gerou uma foliação penetrativa, mas rotacionou a foliação principal arqueana $\left(\mathrm{S}_{\mathrm{N}}\right.$ ). A lineação $\mathrm{Lm} / \mathrm{e}_{\mathrm{n}-1}$ é dada pelo estiramento de quartzo e feldspatos nos granitóides, estrias de movimento em formações ferríferas bandadas e alinhamento de agulhas de anfibólio em metabasaltos. A figura $2 a$ agrupa medidas de $\mathrm{Lm} / \mathrm{e}_{\mathrm{n}-1}$ e a $\mathrm{S}_{\mathrm{p}}$ e indica que as feições estruturais de $D_{n-1}$ resultaram de deslocamento reverso sistemático para norte, movimentos transcorrentes sinistrais $\left(» \mathrm{~N} 30^{\circ} \mathrm{E}\right)$ e dextrais $\left(» \mathrm{~N} 30^{\circ} \mathrm{W}\right)$ e oblíquos sinistrais ao longo de planos $\mathrm{NE}$ e oblíquos dextrais em planos NW. Por conseguinte, esta família de estruturas responde a um vetor compressivo de direção aproximada NS. As dobras $F_{n-1}$ são apertadas a isoclinais e, quando assimétricas, têm vergência para norte. A atitude da foliação principal $\left(S_{p}=S_{n-1}\right.$, Fig. 2b) se concentra em um máximo em $N 78^{\circ} \mathrm{W} / 15^{\circ} \mathrm{SW}$ e permite traçar duas guirlandas, uma de $p_{1}=N 55^{\circ} \mathrm{E} / 73^{\circ} \mathrm{SE}$ e $b_{1}=17^{\circ} / \mathrm{N} 35^{\circ} \mathrm{W}$ e outra de $p_{2}$ $=\mathrm{N} 54^{\circ} \mathrm{E} / 80^{\circ} \mathrm{NW} \mathrm{e} \mathrm{b}_{2}=10^{\circ} / \mathrm{S} 36^{\circ} \mathrm{E}$, onde $\mathrm{b}_{1}$ e $\mathrm{b}_{2}$ são eixos de dobras, superpostos a $\mathrm{S}_{n-1}$, com duplo caimento.

As principais zonas de cisalhamento (Fig. 1) de $D_{n-1}$ são as Zonas de Cisalhamento Transcorrente Dextral (ZCT (n-1 ) Carroça, Engenho Velho e João Leite. A Zona de Cisalhamento Carroça é contato meridional da faixa Guarinos com o Bloco Moquém, tem cerca de $2 \mathrm{~km}$ de largura e $40 \mathrm{~km}$ de extensão, se orientada segundo $\mathrm{N} 30^{\circ}-60^{\circ} \mathrm{W}$ e tem caráter dextral (Pulz 1990). A Zona de Cisalhamento Engenho Velho (H. Jost, inédito) é interna à faixa Guarinos, subparalela à Zona de Cisalhamento Carroça, dextral e consiste de um feixe de zonas menores, responsável pelo deslocamento lateral entre as diversas unidades estratigráficas. A Zona de Cisalhamento João Leite é o contato entre o Complexo Hidrolina e a faixa de Pilar de Goiás e também apresenta orientação e cinemática palcoproterozóicas e intensa deformação dúctil. As principais klippen (Fig. 1) interpretadas como resultantes de $\mathrm{D}_{\mathrm{n}-\mathrm{s}}$, compreendem (i) a Seqüência Morro Escuro, a qual cobre parci- almente o contato do limite sul da faixa Guarinos com o Complexo Caiamar e (ii) a estreita faixa de rochas calcissilicáticas situadas na porção centro-leste da faixa de Pilar de Goiás.

A atividade magmática paleoproterozóica na região se manifesta por intrusões de albita granitos e do Diorito Posselândia. Datações U$\mathrm{Pb}$ SHRIMP em zircão indicam que um corpo de albita granito que intrude o greenstone belt Pilar de Goiás tem data de $2.145 \pm 12 \mathrm{Ma}$ (Queiroz 2000), o Diorito Posselândia de 2.146 $\pm 1,6 \mathrm{Ma}$ (Pimentel et al. 1990, Jost et al. 1993). Além das evidências estruturais e magmáticas, também ocorrem efeitos retrometamórficos desta época, como evidenciado pela idade de $2.011 \pm 15 \mathrm{Ma}$ (Queiroz et al. 2000) de parte da titanita dos Gnaisses Crixás Açu.

Neoproterozóico A deformação neoproterozóica impressa nos terrenos arqueanos da área está representada por um acervo estrutural vergente para o Cráton do São Francisco e reúne as fases $D_{n}$ e $D_{n+1}$ (Queiroz 1995). A fase $D_{n}$ foi reversa e evoluiu para a $D_{n+1}^{n+1}$ transcorrente. Em ambas, a intensidade foi acentuada.

A família de estruturas desta fase inclui dobras $\left(F_{0}\right)$, lineações minerais e de estiramento $\left(\mathrm{Lm} / \mathrm{e}_{\mathrm{n}}\right)$, Zonas de Cisalhamento Reverso $\left(Z C R_{n}\right)$ e uma foliarão $S_{n}=S_{n}$ resultante da rotação de foliasses mais antigas. As relações entre $S$ e ${ }^{n}$ Lm/e mostram movimentos oblíquos sinistrais ao longo de planos $\mathrm{NW}$ e dextrais nos NE. As dobras $\mathrm{F}_{\mathrm{n}}$ são, em geral, centimétricas a decimétricas, apertadas a isoclinais, com espessamento da zona de charneira (classes 2 e 3, Ramsay 1967). Quando assimétricas, têm vergência para quadrantes de leste. A atitude das charneiras $\mathrm{Lb}$ se concentra em $19^{\circ} / \mathrm{S} 20 \mathrm{~W}$ e $36^{\circ} / \mathrm{N} 37 \mathrm{~W}$ (Fig. 3a). Em locais com deformação mais intensa, $\mathrm{Lb}$ coincide com lineações mineral e de estiramento $\left(\mathrm{Lm} / \mathrm{e}_{\text {) }}\right.$ ) genericamente orientadas segundo $\mathrm{N} 40^{\circ} \mathrm{W}$. O máximo em torno de $\mathrm{S} 20^{\circ} \mathrm{W}$ é compatível com deformação reversa e transporte de direção NW-SE. Durante essa fase, as foliações mais antigas foram discretamente rotacionadas em toda a área, mas de forma proeminente no interior de estreitas zonas nas quais, subseqüen-
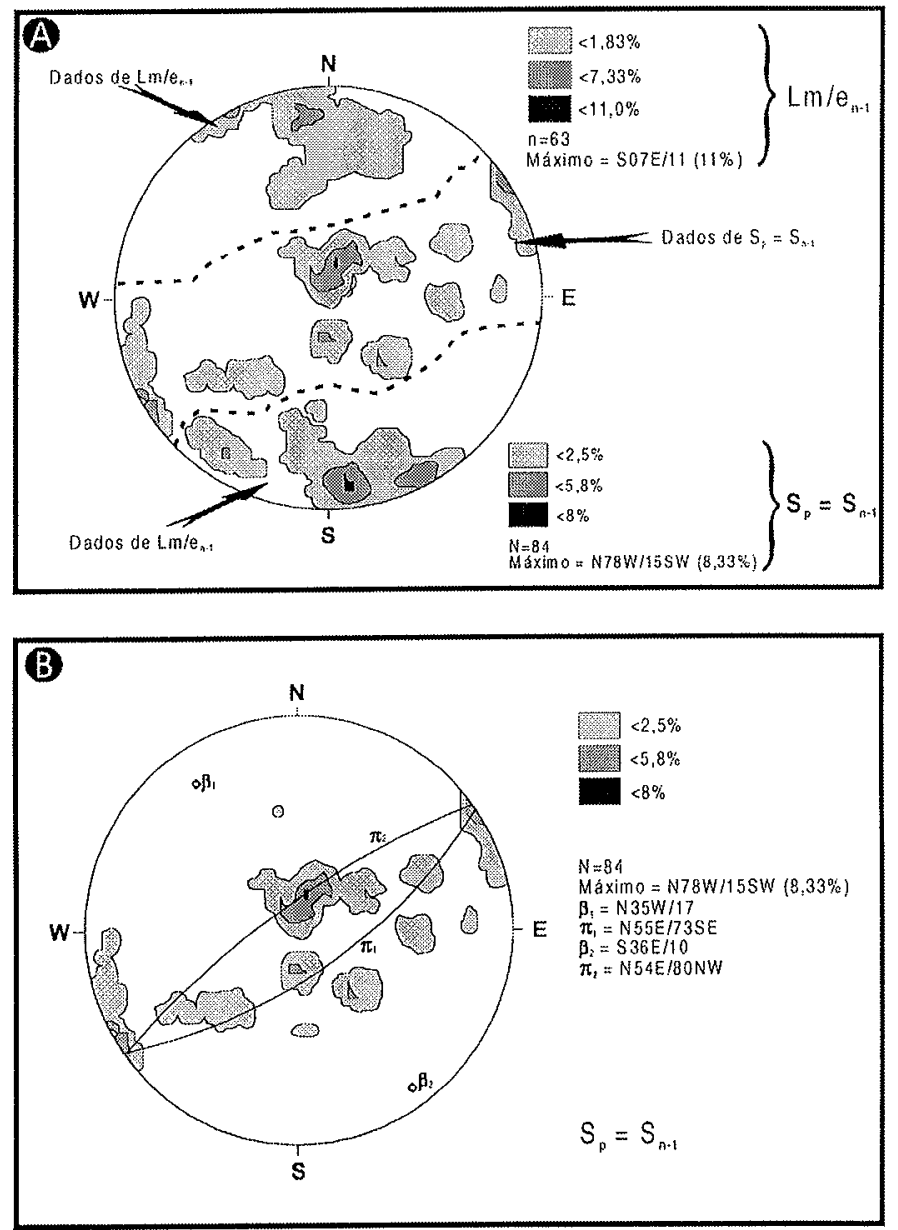

Figura 2 - (a) Estereograna sinóptico, combinando a foliação $S_{p}=S_{n-1}$ e a Lineação Lm/e $e_{n-1} ;(b)$ Estereograma sinóptico da foliação $S_{p}=S_{n-1}$. 

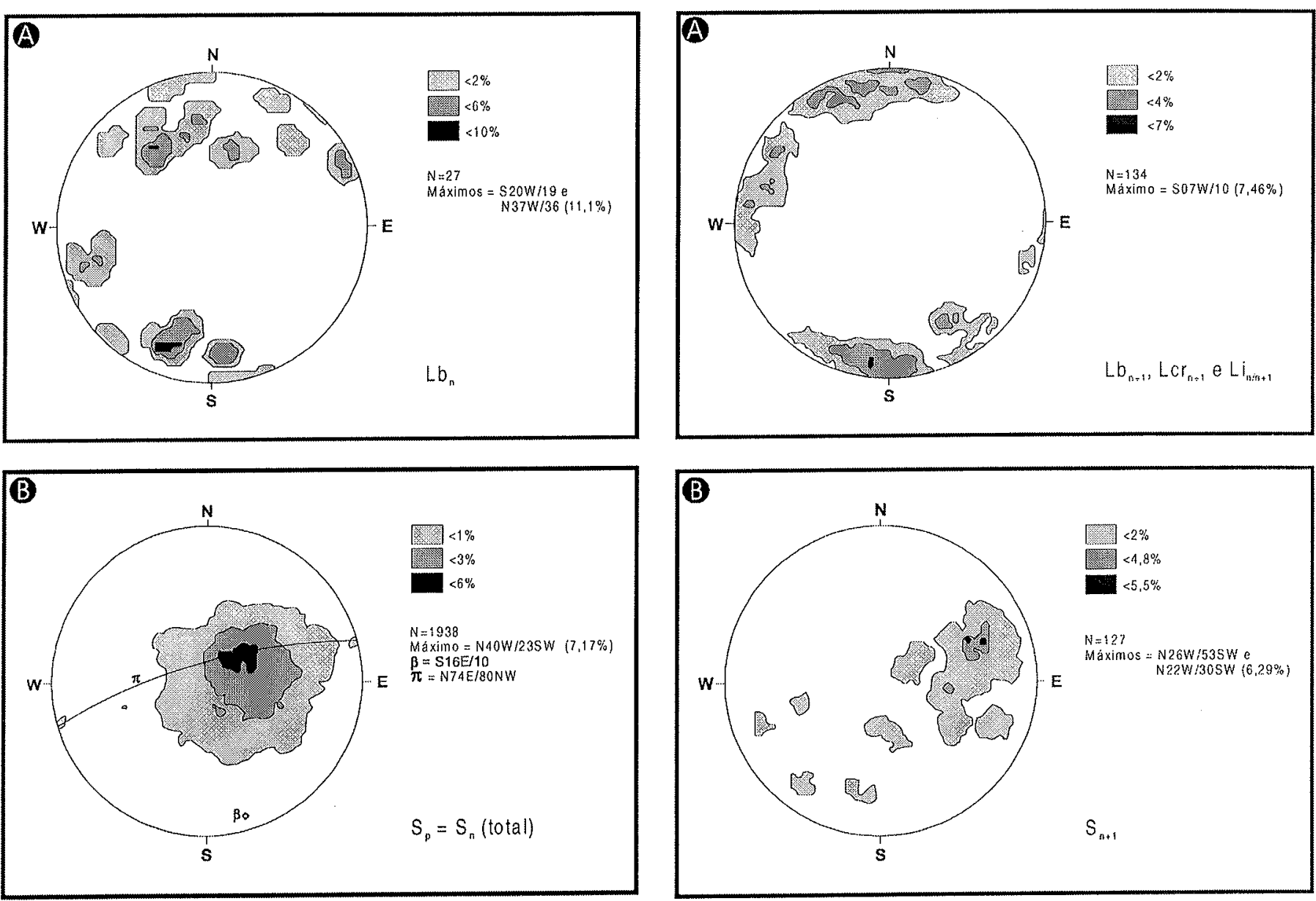

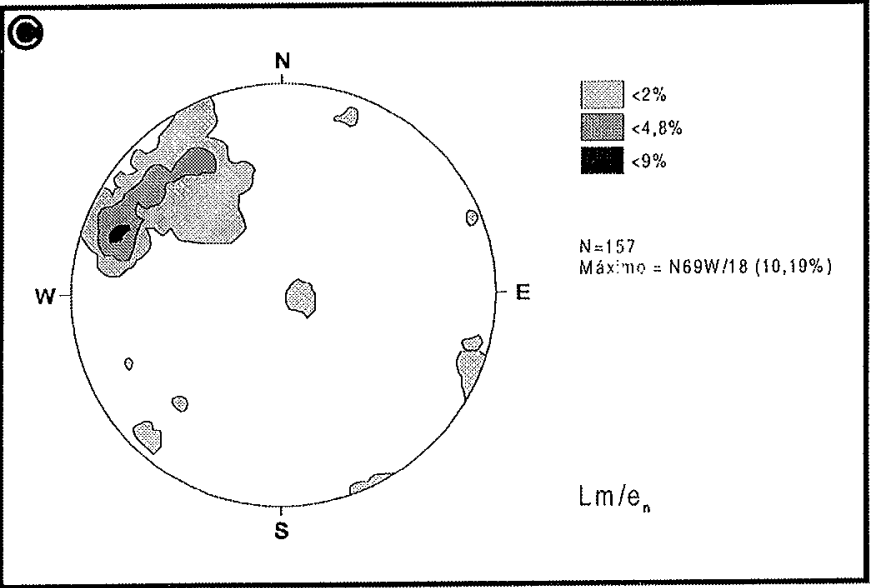

Figura 3 - (a) Estereograma sinóptico da lineação Lbor (b) Estereograma sinóptico da foliação $S_{p}=S_{n} ;$ (c) Estereograma sinóptico da lineação $\mathrm{Lm} / \mathrm{e}_{\|}$.

temente, se concentrou $\mathrm{D}_{\mathrm{n}+1}$ sob a forma de corredores transpressivos. $O$ efeito combinado de ambas fases sobre foliações mais antigas consta da figura $3 \mathrm{~b}$, que mostra um máximo em $N 40^{\circ} \mathrm{W} / 23^{\circ} \mathrm{SW}$, com atitudes de $\mathrm{S}$ distribuídas em guirlanda com $\pi=\mathrm{N} 74^{\circ} \mathrm{E} / 80^{\circ} \mathrm{NW}$ e $\beta=10^{\circ} \%$ $\mathrm{S} 16^{\circ} \mathrm{E}$. A lineação $\mathrm{Lm} / \mathrm{e}_{\mathrm{n}}$ se materializa em lineações minerais e de agregados e caudas de estiramento de fenoclastos e fenoblastos e tem máximo em $18^{\circ} / \mathrm{N} 69 \mathrm{~W}$ com dispersão até $\mathrm{N} 20^{\circ} \mathrm{W}$ (Fig. 3c).

As principais zonas de cisalhamento reversas $\left(Z_{C R}\right)$ de $D_{n}$ (Fig, 1) compreendem o Cinturão de Cisalhamento de Empurrão Córrego Geral-Meia Pataca, localizado no greenstone belt Crixás (Magalhães 1991), a situada imediatamente a norte de Guarinos (Jost et al. 1995) e associada ao Albita Granito Santo Antônio, e a zona de cisalhamento aqui denominada Três Buracos, localizada em Pilar de Goiás. As ZCR ${ }_{n}$
Figura 4- (a) Estereograma sinóptico das lineações $L b_{n+1}, L c r_{n+1}$ e $L i_{n+1} ;(b)$ Estereograma sinóptico da foliação $S_{n+1}$

contêm evidências de deformação dúctil, desenvolvimento de rampas frontais, laterais e oblíquas sem rompimento significativo ou grandes rejeitos do meio onde se alojam.

A associação da ZCR de Guarinos e o Albita Granito Santo Antônio implica em relação de atividade magmática com o descolamento. A idade de zircões metamorfizados de uma amostra de gnaisses granodioríticos do Bloco Moquém, coletada a cerca de $200 \mathrm{~m}$ da frente de empurrão, geraram um intercepto inferior concordante de $590 \pm 10 \mathrm{Ma}$ (Queiroz 2000), indicando que a falha e a intrusão são do Neoproterozóico.

As estruturas de $D_{n+1}$ compreendem dobras $\left(F_{n+1}\right)$, lineações de interseção $\left(\mathrm{Li}_{n / n+1}\right)$, de crenulação $\left(\mathrm{Lcr}_{n+1}\right)$ e eixo de dobras $\left(\mathrm{Lb}_{\mathrm{n}+1}\right)$, uma foliação plano axial $\left(S_{n+1}\right)$ e zonas de cisalhamento transcorrente $\left(\mathrm{ZCT}_{\mathrm{n+1}}\right)$. Esta fase é interpretada como o final da deformação neoproterozóica e responsável pela nucleação do Corredor Transpressivo Ribeirão das Antas/Rio Vermelho, de direção $\mathrm{N} 50^{\circ} \mathrm{W}$ e caráter sinistral. A esta estrutura é atribuído um vetor compressivo de direção aproximadamente EW. As dobras $\mathrm{F}_{n+1}$ são abertas a suaves e menos frequientes que as $\mathrm{F}_{\text {. }}$. Os seus eixos săo do tipo $b$ e sua orientação é consistente com a dăs lineações de interseção e de crenulação entre esta fase e a $D_{u}\left(\operatorname{Lcr}_{n+1}\right)$, as quais mostram um máximo em $10^{\circ} /$ S0 $7^{\circ} \mathrm{W}$, com dispersăo entre os azimutes $270^{\circ}$ e $320^{\circ}$ (Fig. 4 a). Em afloramento se observa a comum ocorrência de par sincrônico de lineaçōes de crenulação ( Lcr $\left._{n+1}\right)$ NS e EW. A foliação $S_{n+1}$ é normalmente uma clivagem de crenulação, subordinadamente foliação mal

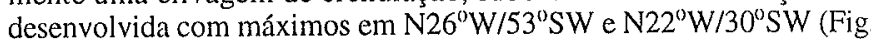
$4 \mathrm{~b}$ ). As Zonas de Cisalhamento Transcorrente (ZCT ${ }_{\text {H1 }}$ ) desta fase são de primeira e terceira ordens (sensu Moody \& Hill' 1956) e caráter dúctil-rúptil. As de primeira ordem tem orientação $N 50^{\circ} \mathrm{W}$ e são sinistrais e as de terceira ordem NS e dextrais.

O Corredor Transpressivo Ribeirão das Antas/Rio Vermelho (Queiroz 1995, Queiroz et al. 1995) é a feição dominante de $\mathrm{D}_{\mathrm{n}+\mathrm{l}}$, e 
corta a área desde a faixa Crixás, a nordeste, até o Grupo Araxá, a sul da faixa Pilar de Goiás (Fig. 1), prolongando-se até o Complexo de Barro Alto. A estrutura tem orientação $N 50^{\circ} \mathrm{W}$ e caráter sinistral. $\mathrm{O}$ corredor é estreita faixa limitada por falhas discretas e descontínuas, com deslocamento visível em afloramentos, imagens TM-LANDSAT 5, SLAR-GEMS 1000, SAR-JERS-1 e magnetométricas (Blum 1995). Sua característica mais significativa é a rotação de estruturas mais antigas. A norte, $S$ descreve uma trajetória com concavidade voltada para ENE e a sul para WSW. O seu interior contem zonas de cisalhamento, tais como a Zona Mestra (Queiroz 1995, Queiroz et al. 1995), localizada no flanco noroeste da faixa Crixás. Outras zonas de cisalhamento atribuídas a $\mathrm{D}_{\text {1 }}$ (Queiroz 1995) compreendem a do Córrego Eleutério e a do Ribeirão Alagado. Os lineamentos e a trajetória de $\mathrm{S}$ mostram a existência de equivalentes segundo $\mathrm{N} 50^{\circ} \mathrm{E}$, dextrais, mas pouco expressivos em campo. As zonas de cisalhamento de terceira ordem são discretas, têm extensão reduzida e são subverticais e dextrais. Estas ocorrem em rochas arqueanas e proterozóicas adjacentes, tais como nas Sequiências Santa Terezinha e Mara Rosa, a norte, e no Arco Magmático, a sul, na região de Jussara (Pimentel et al. 1996). A Zona de Cisalhamento Garimpo da Lavra, situada na porção norte do greenstone belt Crixás (Fig. 1), exemplifica as zonas de cisalhamento de terceira ordem.

MATERIAL E MÉTODOS A análise de feições lineares tem sido motivo de controvérsias desde o clássico artigo de Hobbs (1911), que mostrou a correspondência entre feições fisiográficas lineares e introduziu o conceito de ordens de feições lineares. A discussão tomou impulso a partir de 1972, durante o imageamento, em escala global, da superfície da Terra por satélites de sensoriamento remoto.

O ceticismo decorreu da grande densidade de feições lineares, de geometria e relações geológicas de interpretação complexas, comumente registradas em imagens. Muitas interpretações foram consideradas questionáveis pela falta de critérios de estabelecimento da correspondência entre as diferentes classes de feições lineares e seus significados geológicos e de técnicas de extração, seleção de bandas espectrais e escalas adequadas para a sua análise. Contudo, a continuidade dos programas de sensoriamento remoto e a adoção de sensores orbitais de melhor resolução, motivou um aprofundamento e a validação dos métodos de interpretação (Soares et al. 1981, Veneziani 1987). $\mathrm{O}$ avanço tecnológico mostrou a utilidade das imagens em mapeamento geológico e análise estrutural de lineamentos, quando, então, o termo Lineamento, como identificado em imagens, passou por redefinição e em substituição ao termo feição linear. O'Leary et al. (1976) o definem como uma feição da superfície do Globo Terrestre, mapeável, simples ou composta, de traço retilíneo ou suavemente curvo, que difere de feições adjacentes e presumivelmente reflete um fenômeno de subsuperfície.

Atualmente, é inquestionável que a identificação de lineamentos crustais visíveis na escala de imagens orbitais favorece a demarcação de domínios estruturais de larga escala, de forma rápida e eficiente, não obtida por outros meios. Também disponibilizou à análise estrutural e tectônica uma nova categoria de dados que, por análise de interseções

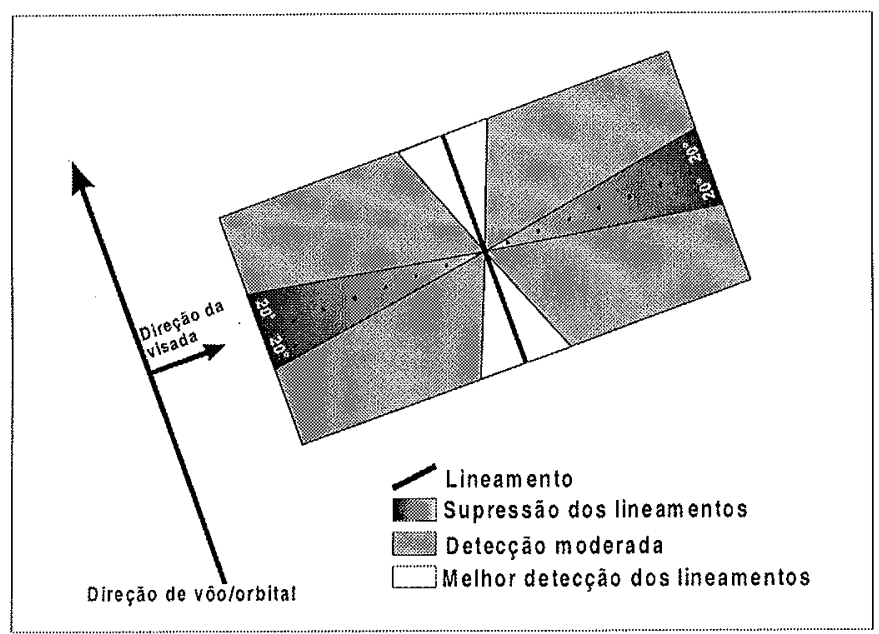

Figura 5 - Diagrama mostrando a supressão de lineamentos e destacando os melhores angulos para deteção de feições (modificado de RADARSAT International 1997) e configurações de lineamentos, contribui para a identificação de áreas potencialmente favoráveis para recursos minerais.

Segundo Sawatzky \& Lee (1974), a análise de elementos morfoestruturais (lineamentos), depende do realce do relevo propiciado pelo ângulo de visada, de incidência da radiação eletromagnética (REM) e do realce por sombreamento. Imagens adequadas ao estudo de EMR são aquelas nas quais a elevação e o azimute solar estejam geometricamente arranjados de forma a aumentar o sombreamento da topografia. A priori, ângulos de elevação solar entre $20^{\circ}$ e $30^{\circ}$ fornecem as melhores relações de sombreamento, pois o efeito da iluminação em 3D do relevo é uma relação de intensidade de contraste tonal entre faces opostas do relevo iluminado e sombreado (par claro-escuro). Entretanto, o efeito benéfico da elevação solar pode ser reduzido se $o$ azimute solar não for ortogonal, ou pelo menos oblíquo, às estruturas imageadas. Especialmente em lineamentos, na medida em que estes alinham na direção de visada, reduz-se o contraste tonal das faces opostas do relevo, reduzindo a possibilidade de sua detecção (Fig. $5)$.

Em sensores passivos, mudanças sazonais que resultam em alterações da elevação e do azimute solar modificam significativamente os valores dos pixels na data de obtenção da imagem. Em sensores ativos, como o radar, a direção azimutal de iluminação do pulso da REM emitido pelo sensor determina a intensidade do realce dos EMR e, por operarem com grandes comprimentos de onda, condições atmosféricas adversas (nuvens, chuvas, etc.) não afetam o imageamento. Embora o sinal de retorno dependa da constante dielétrica dos materiais e da rugosidade da superfície, a orientação das vertentes é o principal parâmetro na determinação da macroestrutura do relevo. As imagens de radar são, assim, particularmente adequadas ao estudo das feições de relevo (Amaral 1982).

O uso de diferentes sensores possibilita uma avaliação mais crítica na análise de lineamentos. Na presente pesquisa, empregou-se imagens geradas por três sensores, reproduzidas em preto e branco e obtidas pelos satélites SLAR-GEMS 1000, TM-LANDSAT 5 e SAR-JERS-1 (Tabela 1). A imagem SLAR-GEMS 1000 (Folha SD.22-Z-A) e a TMLANDSAT 5 (WRS 222/070) foram interpretadas na escala 1:250.000 e a SAR-JERS 1 (Cena 391/325) na escala 1:100.000. A partir de cada imagem gerou-se um mapa de lineamentos de relevo do Tipo 1, representados por estruturas de extensão regional, caráter dúctil, com foliações, lineações, eixos e flancos de dobras, e que se expressam por relevo positivo ou negativo e acompanhados de bandamento tonal (Amaro \& Strieder 1994).

Observe-se que uma gama de estruturas distintas, resultantes de um mesmo esforço tectônico, pode dar origem a um mesmo lineamento. Por exemplo, um lineamento expresso por uma falha, num determinado local, pode progredir para uma zona de cisalhamento que, por sua vez, pode dar lugar a uma foliação principal.

RESULTADOS Os resultados da análise constam das figuras 6,8 , e 10 , que, apesar de semelhantes, contrastam com a textura das imagens das figuras 7,9 e 11), onde a densidade espacial e orientação vetorial dos lineamentos (Fig.12) mostra particularidades relevantes.

A análise visual das imagens e mapas de lineamentos (Figs. 6 a 11) mostra que os lineamentos se orientam segundo NE e NW, com variação de até $15^{\circ}$. Estruturas regionais, como o Corredor Transpressivo Ribeirão das Antas/Rio Vermelho e as Zonas de Cisalhamento Córrego Eleutério e João Leite se orientam segundo $N 50^{\circ}-60^{\circ} \mathrm{W}$ e $\mathrm{N} 20^{\circ}-30^{\circ} \mathrm{W}$. Apesar de pouco evidentes em campo, as estruturas $\mathrm{NE}$ são frequientes nas imagens segundo $\approx N 30^{\circ} \mathrm{E} e \approx N 70^{\circ} \mathrm{E}$.

Os histogramas de freqüência de azimutes dos lineamentos (Fig. 12) mostra uma forte tendência bimodal. As modas nas três imagens

Tabela 1 - Especificações técnicas dos sensores utilizados na análise de lineamentos.

\begin{tabular}{|l|c|c|c|}
\hline Especificação Técnica & $\begin{array}{c}\text { TM- } \\
\text { LANDSAT }\end{array}$ & $\begin{array}{c}\text { SLAR- } \\
\text { GEMS 1000 }\end{array}$ & $\begin{array}{c}\text { SAR- } \\
\text { JERS-1 }\end{array}$ \\
\hline altitude $(\mathrm{km})$ & 978 & 11 & 568 \\
\hline bandas espectrais & 4 & $\mathrm{X}$ & $\mathrm{L}$ \\
\hline comprimento de onda $(\lambda)$ & $0,76 a 0,90 \mu \mathrm{m}$ & $3,20 \mathrm{~cm}$ & $23,5 \mathrm{~cm}$ \\
\hline largura da faixai imageada $(\mathrm{km})$ & 185 & 37 & 75 \\
\hline ângulo de iluminaçăo/depressão $\left(^{\circ}\right)$ & EL $37^{\circ}, \mathrm{AZ} 46^{\circ}$ & 13 & 52 \\
\hline direção de vôo/orbital & descendente & $\mathrm{NS}$ & descendente \\
\hline direçăo da visada & NADIR & EW & EW \\
\hline resolução espacial $(\mathrm{m})$ & 30 & 16 & 18 \\
\hline
\end{tabular}




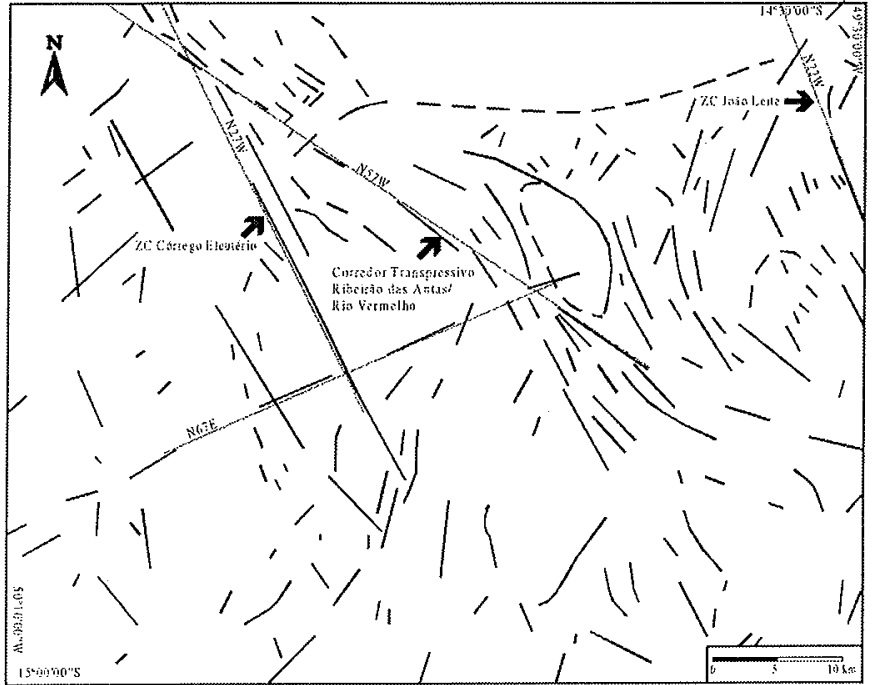

Figura 6-Mapa de lineamentos, extraidos de imagen-mosaico SLAR-GEMS $1000,1: 250.000$ (Folha SD.22-Z-A).

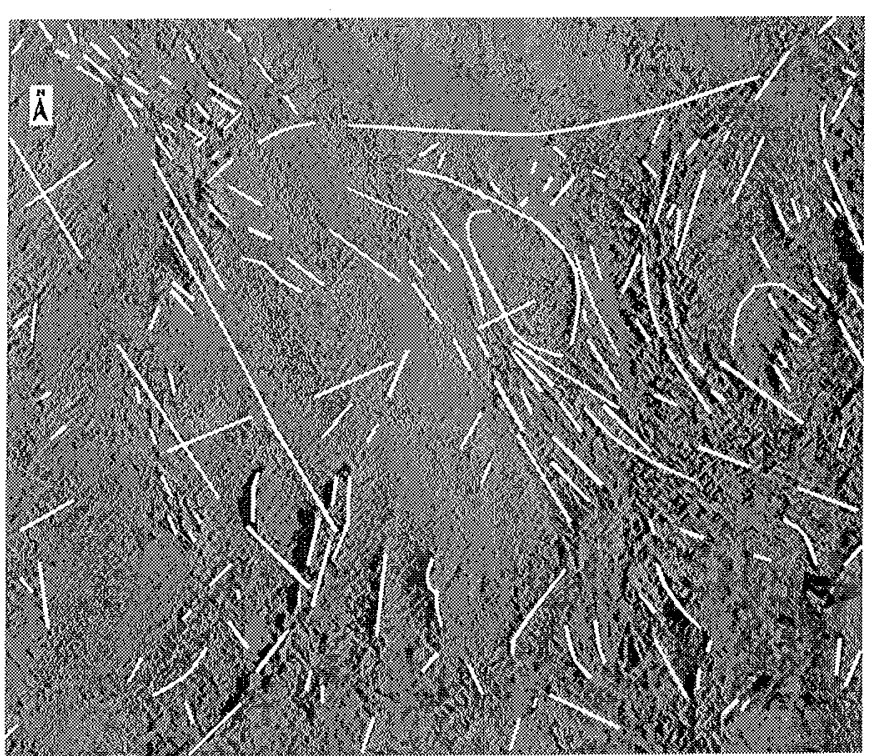

Figura 7 - Reprodução da imagent-mosaico SLAR-GEMS 1000, 1:250.000 (Folha SD.22-Z-A).

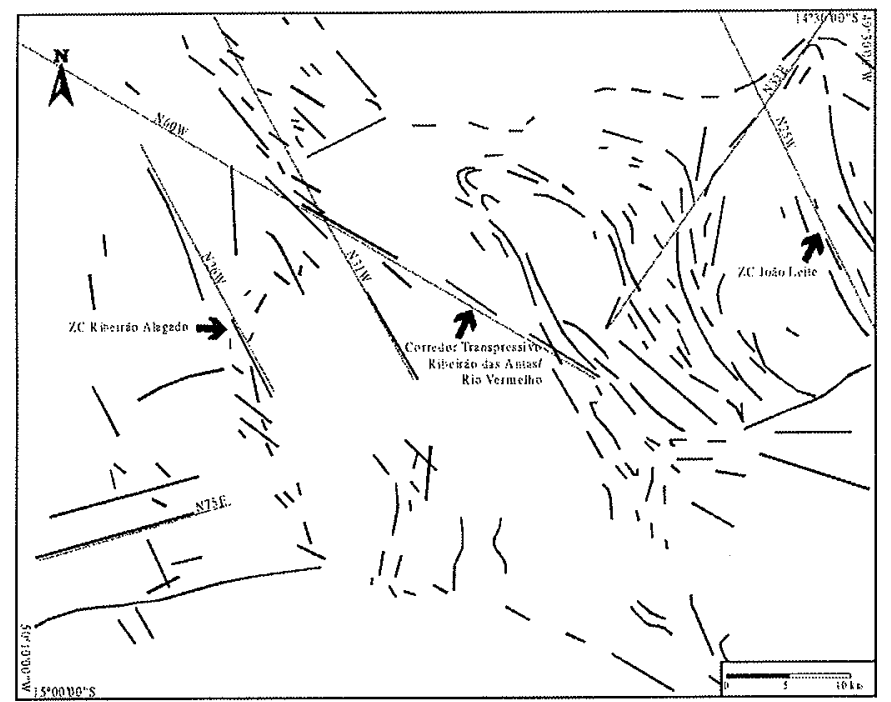

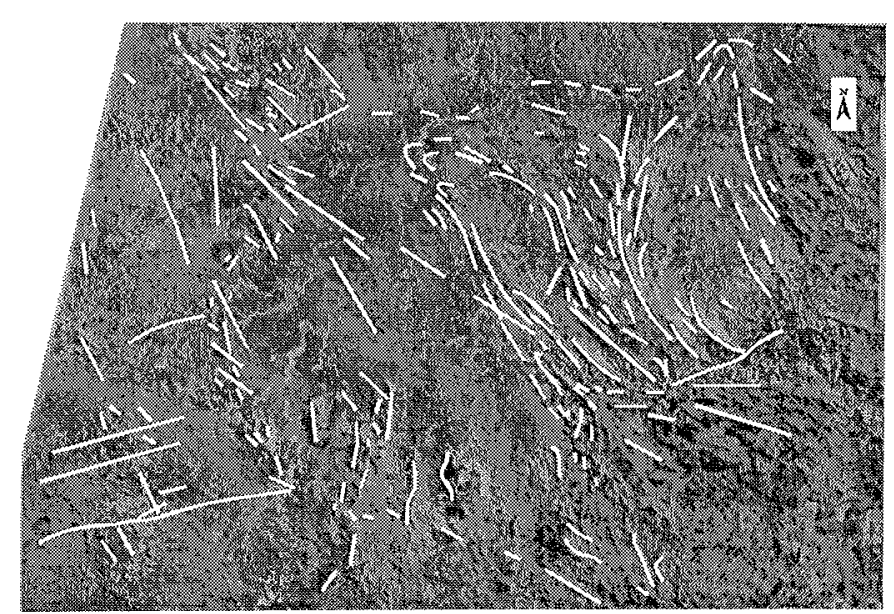

Figura 9 - Reprodução da imagem TM-LANDSAT 5, 1:250.000 (WRS 222/ 070).

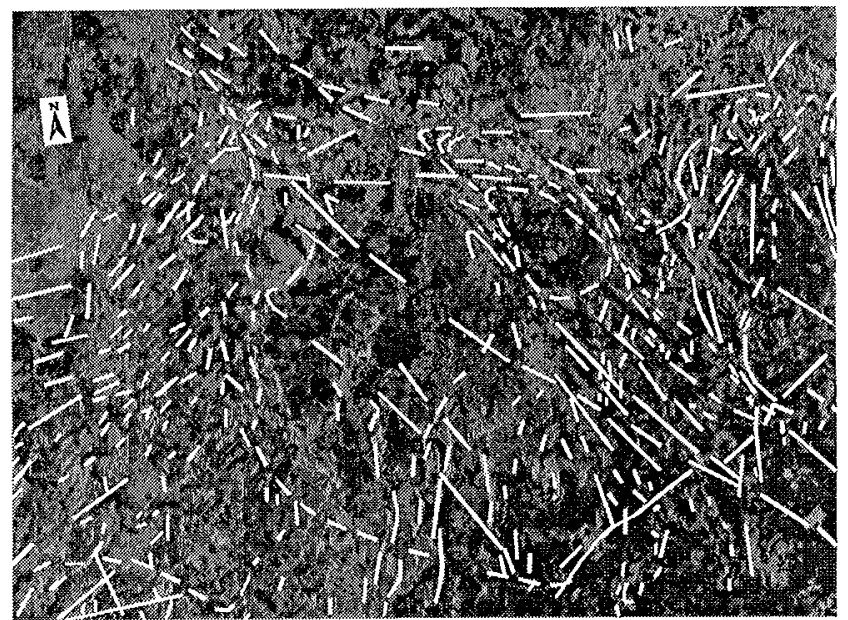

Figura 10 - Mapa de lineamentos, extraídos de imagem SAR-JERS-J, I:J00.000 (Cena 39l/325).

Figura 8 - Mapa de lineamentos, extraidos de imagem TM-LANDSAT 5 , 1:250.000 (WRS 222/070). 
situam-se em torno de $\mathrm{N} 50^{\circ}-60^{\circ} \mathrm{W}$ e entre $\mathrm{N} 45^{\circ} \mathrm{E}$ e $\mathrm{N}^{\mathrm{\prime}} 65 \mathrm{E}$. As freqüências extremas, representadas pelas direções $N 80^{\circ} \mathrm{E}$ e EW, não foram consideradas por corresponderem a ruídos na imagem SARJERS 1 e não a feições geológicas. As orientações $\mathrm{N} 20^{\circ}-30^{\circ} \mathrm{W}$ e $\mathrm{N} 30^{\circ} \mathrm{E}$ são estatisticamente pouco expressivas, apesar da ocorrência de estruturas $\approx \mathrm{N} 30^{\circ} \mathrm{W}$ em afloramentos.

$\mathrm{O}$ par de lineamentos $\mathrm{N} 50^{\circ}-60^{\circ} \mathrm{W}$ e $\approx N 70^{\circ} \mathrm{E}$ freqüentemente seciona o par $\mathrm{N} 20^{\circ}-30^{\circ} \mathrm{W} \mathrm{e} \approx \mathrm{N} 30^{\circ} \mathrm{E}$, sugerindo que o primeiro é, provavelmente, mais jovem. $O$ ângulo agudo de $60^{\circ}$ entre ambos sistemas sugere que estes são pares conjugados. A bissetriz do ângulo agudo do sistema $\mathrm{N} 30^{\circ} \mathrm{W}-\mathrm{N} 30^{\circ} \mathrm{E}$ tem orientação NS e, a do sistema $\mathrm{N} 50^{\circ} \mathrm{W}$ $\mathrm{N} 70^{\circ} \mathrm{E}, \mathrm{N} 80^{\circ} \mathrm{W}(\approx \mathrm{EW})$.

Comparativamente, a densidade de lineamentos $(0,06$ lineamentos/ $\mathrm{km}^{2}$ ) obtida a partir da figura 6 , transcrita da imagem de radar SLARGEMS 1000, é semelhante à de lineamentos da figura 8. Contrariamente aos demais, a figura 6 mostra um realce do relevo plano dos terrenos granito-gnáissicos, pois menores comprimentos de onda de radar destacam superfícies menos rugosas. A figura 8, obtido da imagem TM-LANDSAT 5, mostra uma densidade de lineamentos menor $\left(0,05\right.$ lineamentos $\left./ \mathrm{km}^{2}\right)$ e, exceto no Bloco Moquém, destaca os greenstone belts por realce de relevo. Dentre os documentos, o da figura 10, obtido a partir da imagem do radar SAR-JERS-1, é o que apresenta a maior densidade $\left(0,13\right.$ lineamentos $\left./ \mathrm{km}^{2}\right)$.

Nos três mapas destaca-se um importante lineamento $\mathrm{N}^{0} 50 \mathrm{~W}$ que inicia no greenstone belt de Crixás, corta os de Guarinos e Pilar de Goiás e que é representado pelo Corredor Transpressivo Ribeirão das Antas/Rio Vermelho. Nas figuras 6 e 8 também são visíveis as Zonas de Cisalhamento Córrego Eleutério e Ribeirão Alagado, orientadas segundo $\mathrm{N} 30^{\circ} \mathrm{W}$. Em afloramento, as três feições têm cinemática sinistral. Por outro lado, os três mapas, em especial os dois primeiros, também registram lineamentos segundo $\approx N 70^{\circ} \mathrm{E}$.

A análise de três imagens geradas por diferentes sensores possibilitou a identificação de um conjunto mais completo de lineamentos para subsidiar aspectos da geologia estrutural da região. As imagens TM-LANDSAT 5 e SAR-JERS-1 realçam as formas de relevo e também os contrastes tonais entre unidades distintas. A imagem SARJERS- 1 apresenta a maior densidade de informações e a SLAR-GEMS 1000 mostra, de forma mais nítida, as variações texturais do relevo e possibilita inferir relações de truncamento e superposição entre os sistemas de lineamentos.

CONCLUSÕES A imagem do radar SAR-JERS-1 apresenta maior densidade de informações na escala de 1:100.000 e é mais recomendável para a interpretação de estruturas com expressão topográfica. A do radar SLAR-GEMS 1000, devido ao seu comprimento de onda menor, favorece realce textural do relevo, especialmente em áreas arrasadas. A imagem TM-LANDSAT 5 contem estruturas que também constam da radar. Os resultados de interpretação dessas imagens mostra a sua utilidade em trabalhos de geologia estrutural, uma vez que os mapas gerados subsidiaram uma melhor compreensão do arcabouço geométrico da área estudada, mas que somente se completou com dados de campo, insubstituíveis quando se trata da interpretação cinemática

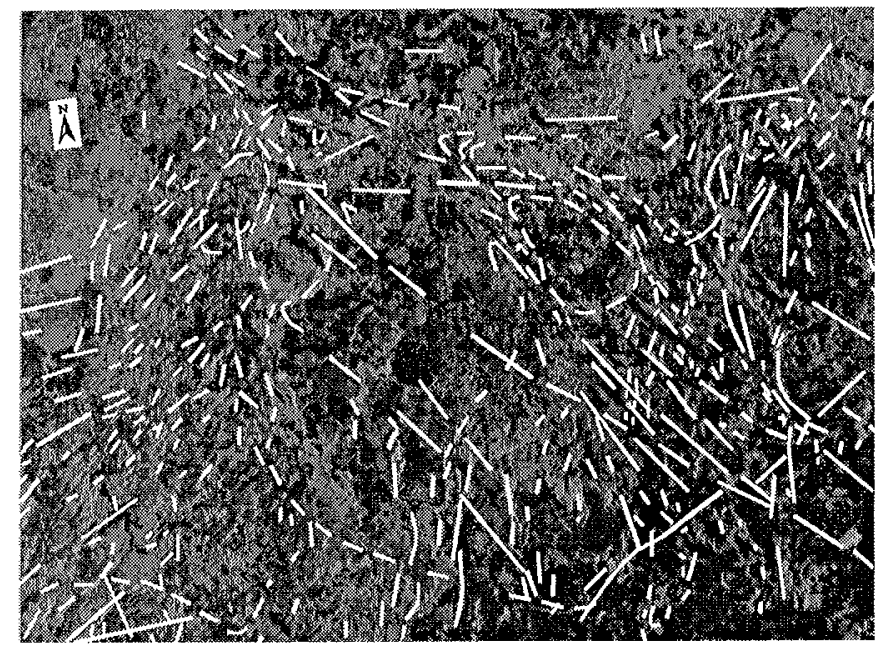

Figura II - Reprodução da imagem SAR-JERS-J, I:100.000 (Cena 39I/325).
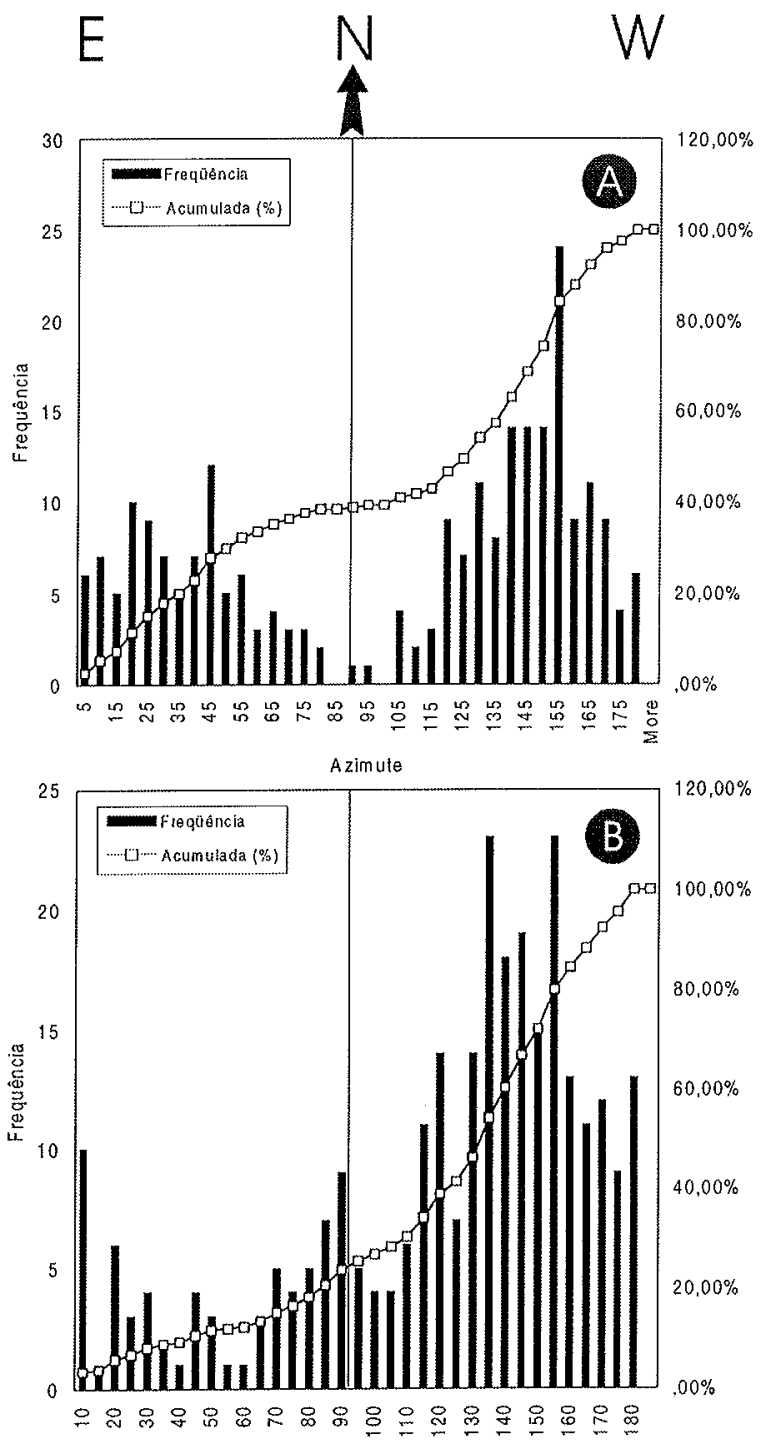

Azimute

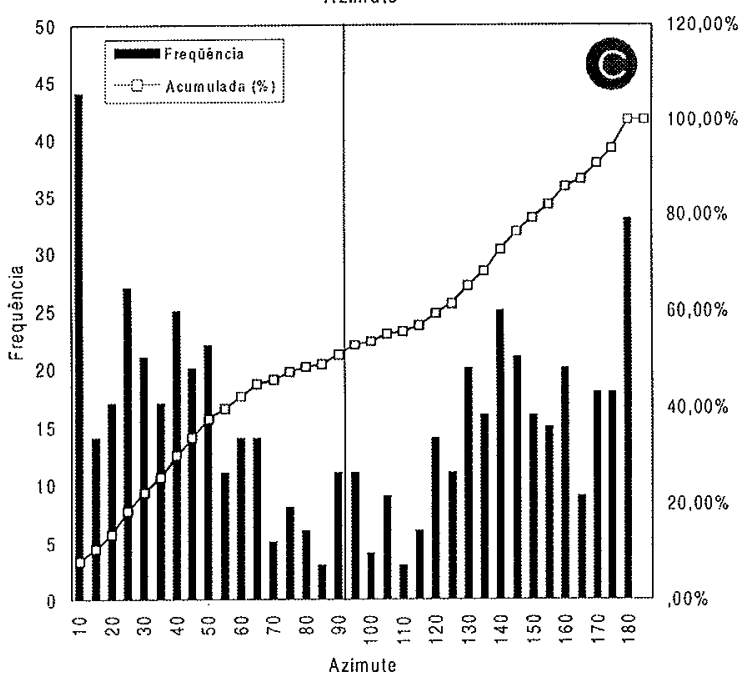

Figura 12 - Histogramas dos azimutes dos lineamentos estruturais. (a) Histograma dos lineamentos da imagem SLAR-GEMS 1000. (b) Histograma dos lineamentos da imagem TM-LANDSAT 5. (c) Histograma dos lineamentos da imagem SAR-JERS I 
A análise das imagens SLAR-GEMS 1000, TM-LANDSAT 5 e SAR-JERS-1 mostra que a porção setentrional dos terrenos arqueanos de Goiás contêm dois pares principais de sistemas de lineamentos. Os dados de campo mostram que os lineamentos das figuras 6,8 e 10 resultam, fundamentalmente, do traço da foliação principal $\left(S_{p}\right)$ e/ou zonas de cisalhamento, foliação essa rotacionada e recristalizada a cada nova fase de deformação. A cinemática das zonas de cisalhamento transcorrentes $\left(\mathrm{N} 50^{\circ} \mathrm{W}-\mathrm{N} 70^{\circ} \mathrm{E}\right.$ e N3 $\left.30^{\circ} \mathrm{W}-\mathrm{N} 30^{\circ} \mathrm{E}\right)$ foi apenas parcialmente interpretada, mas é conspícua em afloramentos. O Corredor Transpressivo Ribeirão das Antas/Rio Vermelho $\left(\mathrm{N} 50^{\circ} \mathrm{W}\right)$ e a Zona de Cisalhamento Ribeirão Alagado (N30 $\mathrm{W}$ ) são, por dados de campo, sinistrais (Queiroz 1995), ao passo que os lineamentos $N 70^{\circ} \mathrm{E}$ são dextrais, como inferido pela interpretação das imagens.

As feições estruturais da área estudada são compatíveis com as da Província Tocantins em geral. A cinemática dos lineamentos transcorrentes do segmento arqueano, como interpretada por Queiroz (1995 e 2000) e Carvalho (1999), particularmente em relação ao movimento sinistral do Corredor Transpressivo Ribeirão das Antas/Rio Vermelho $\left(\mathrm{N} 50^{\circ} \mathrm{W}\right)$ e a lineamentos $\mathrm{N} 30^{\circ}-40^{\circ} \mathrm{W}$, e dextral dos lineamentos $\mathrm{N} 50^{\circ} \mathrm{E}$, são compatíveis, respectivamente, com os sistemas denominados por Fonseca (1996) de Arraias-Campos Belos (N30º W), sinistral, e São Jorge-Alto Paraíso-Cormari $\left(\mathrm{N} 70^{\circ} \mathrm{E}\right)$, CavalcanteTerezina $\left(\mathrm{N} 70^{\circ} \mathrm{E}\right)$ e Padre Bernardo-Cocalzinho $\left(\mathrm{N} 30^{\circ} \mathrm{E}\right)$, dextrais. Assim, os sistemas $\mathrm{N} 30^{\circ} \mathrm{W}-\mathrm{N} 30^{\circ} \mathrm{E}$ e N50 $\mathrm{W}-\mathrm{N} 70^{\circ} \mathrm{E}$ e as estruturas NE são dextrais e as NW sinistrais.

Quanto à idade dos sistemas de lineamentos, os dados de campo mostram que os lineamentos $\mathrm{N} 50^{\circ} \mathrm{W}-\mathrm{N} 70^{\circ} \mathrm{E}$ cortam simultaneamente rochas arqueanas a neoproterozóicas, sendo, portanto, interpretados como correlatos ao Ciclo Brasiliano, com tensor principal segundo $\approx$ EW e vergência para leste, em direção ao Cráton do São Francisco. Estruturas reversas também podem ser atribuídas ao Ciclo Brasiliano, normalmente um pouco mais antigas, mas associadas às estruturas direcionais. O tensor principal do sistema $\mathrm{N} 30^{\circ} \mathrm{W}-\mathrm{N} 30^{\circ} \mathrm{E}$ se orienta segundo NS e é interpretado como do Paleoproterozóico, como indicam os dados geocronológicos apresentados por Queiroz (2000). Entretanto, os lineamentos $\mathrm{N} 30^{\circ} \mathrm{E}$ deste período são sinistrais e os segundo $\mathrm{N} 30^{\circ} \mathrm{W}$ sinistrais, mas com cinemática provavelmente invertida por reativação durante o Ciclo Brasiliano (Queiroz 2000).

Agradecimentos Ao CNPq pelas bolsa de produtividade e a dois revisores anônimos da RBG pela análise crítica e sugestões ao original.

\section{Referências}

Almeida FFM. 1967. Observaçoes sobre o Pré-Cambriano na região central de Goiás. In: SBG, Congr. Bras. Geol., 21, Curitiba, Anais, V.26.

Amaral G. 1982. Radar de Visada Lateral. In; Mantal de Sensoriamento Remoto com Ênfase em Geologia, CNPq, INPE - Comissăo Técnico Científica de Sensoriamento Remoto. p.173-209.

Amaro V.E. \& Strieder A.J. 1994. Análise de fotolineamentos e padrões estruturais em imagens de satélite. In: SBG, Congr. Bras. Geol., 38, Balneário Camboriú, Anais, $443-444$.

Biondi J.C. 1990. Depósitos de esmeralda de Santa Terezinha (GO). Revista Brasileira de Geociências, 20(1-4):7-24.

Brasil 1981. Projeto RADAMBRASIL. Ministério das Minas e Energia. Folha SD.22 Goiás. pp.327.

Carvalho M.T.N. 1999. Integraçâo de dados geológicos, geofisicos e geoquímicos aplica. dos à prospeção de ouro nos greenstone belts de Pilar de Goiás e Guarinos, GO. Instituto de Geociências, Universidade de Brasília, Brasília, Dissertação de Mestrado, 187p.

Danni J.C.M. \& Ribeiro C.C. 1978. Caracterização estratigráfica da Sequiência VulcanoSedimentar de Pilar de Goiás e de Guarinos, Goiás. In: SBG, Congr. Bras. Geol., 30, Recife, Anais, 582-596.

Fonseca M A 1996 . Estilos estruturais e o arcabouco tectônico do segmento setentrional da Faixa Brasília. Instituto de Geociências, Universidade de Brasília, Brasília, Tese de Doutoramento, $172 \mathrm{p}$.

Hobbs W.H. 1911. Repeating patterns in the relief in the structure of the land. Bulletin of the Geological Society of America, 22:123-176.

Jost H. 2000 The Guarinos greenstone belt: two contrasting stratigraphic and structural domains juxtaposed by a strike-slip fault. (em preparação)

Jost, H.; Vargas, M.C.; Fuck, R.A ., Kuyumjian, R.M. \& Pires, A.C.B. 1994a. Relaçōes de contato, litologias, geologia estrutural e geofísica do Bloco Arqueano do Moquém, Crixás, Goiás. SBG Simpósio de Geologia do Centro-Oeste, IV, Brasília, Resumos Espandidos, p. $15-17$.

Jost, H.; Carmelo, A.C.\& Menezes, P.R. 1994b. Litologias, relaçŏes de contato e estruturas do Bloco do Caiamar, Crixás, Goiás. Simpósio Geologia Centro-Oeste,4, Brasília, Boletim de Resumos Expandidos, p. 18-20.

Jost H. \& Oliveira A.M. 1991. Stratigraphy of the greenstone belts, Crixás region, Goiás, Central Brazil. Journal of South American Eath Sciences, 4(3):201-214.

Jost H. Kuyumijan R M. Freitas A.S. Costa A L.C. Nascimento C.T.C., Vasconcelos F.M., Galotti Neto L., Martins M.C.M.; Carvalho M.N. \& Condé V.C. 1995. Geologia da porção norte do Greenstone Belt de Guarinos, Goís. Revista Brasileira de Geociências. 25(1):51-60.

Jost H., Pimentel M.M, Fuck R.A., Danni J.C.M., Heaman L. 1993. Idade U-Pb do Diorito Posselândia, Hidrolina, Goiás. Revista Brasileira de Geociências, 23(4):352-355.

Jost H. Vargas M.C., Gugelmin V., Oliveira S.R.M. 1989. Seqüência Morro Escuro: uma nova unidade estratigráfica do Arqueano/Proterozóico Inferior na região de Crixás. Estado de Goiás. Revista Bravileira de Geociências, 19(3):283-289.

Magalhães LF 1991. Cinturão de Cisalhamento de Empurrão Cómrego Geral - Meia Pataca: Geologia, Deformação, Alteração Hidrotermal e Mineralizações Auriferas'
Associadas (Crixás, Goías). Instituto de Geociências, Universidade de Brasília, Associadas (Crixás, Goíás). Instituto de
Brasília, Dissertação de Mestrado, 233p.

Marshak S., Tinkham D., Alkmim F., Brueckner H., Bornhorst T. 1997. Dome-and-keel provinces formed during Paleoproterozoic orogenic collapse - core complexes, diapirs, or neither?: examples from the Quadrilátero Ferrifero and the Penokean orogen. Geology; 25(5):215-418.
Moody J.D. \& Hill M. 1956. Wrench-Fault Tectonics. Bulletin of the Geological Society of Anterica, 67:1207-1248.

O'Leary D.W., Friedman D.D., Pohn H.A. 1976. Lineament, linear, lineation: some proposed new standarts for old terms. Bulletin of the Geological Society of America. 87:1463-1469

Pimentel MM Fuck R A Silva L J H.D.R 1996. Dados Rb-Sr e Sm-Nd da Região de Jussara-Goiás-Mossâmedes (GO), e o Limite entre Terrenos antigos do maciço de Jussara-Goiás-Mossâmedes (GO), e o Limite entie Terrenos antigos do maciço de
Goiás e o Arco magmático de Goiás. Revista Brasileira de Geociências, 26(2):61Goiâs

Pimentel M.M., Heaman L., Fuck R.A., Danni J.C.M., Jost H. 1990. Idade U-Pb do diorito de Posselândia, Hidrolina, Goiás. In: SBG, Congr. Bras. Geol., 36, Natal, Resumo das Comunicacones, 339

Pulz G.M. 1990. Geologia do Depósito Aurifero Tipo Maria Lazara (Guarinos - Goiás) Instituto de Geociências, Universidade de Brasília, Brasília, Dissertação de Mestrado, 139p.

Queiroz C.L. 1995. Caracterizatão dos dominios estruturais e da arguitetura do Greenstone Belt de Crixás, GO. Instituto de Geociências, Universidade de Brasília, Brasília, Dissertação de Mestrado, $117 \mathrm{p}$.

Queiroz C. L 2000. Evolução Tectono-Estrutural dos Terrenos Graniro-Greenstone Bet de Crixás, Brasil Central. Instituto de Geociências, Universidade de Brasília, Brasília, Tese de Doutoramento, 209p.

Queiroz C. L. Alkmim F.F., Kuyumjian R.M. 1995. Estudo dos lineamentos de relevo da região do Greenstone Belt de Crixás, GO, através de imagens de sensores remotos.

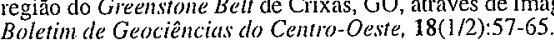

Queir Polymetamorphic history of the Crixás-Açu Gneiss, central Brazil: SHRIMP U-Pb evidence from titanite and zircon. Revista Brasileira de Geociencias, no prelo.

RADARSAT International. 1997. RADARSAT Geology Handbook (available from RADARSAT International).

Ramsay J.G. 1967. Folding and Fracturing of Rocks. New York, McGraw-Hill, 568p.

Resende, M.G.; Jost, H.; Osborne, G.A. \& Mol, A. 1998. The stratigraphy of the Goiás and Faina greenstone belts, Central Brazil: a new proposal. Revisfa Brasileira de Geociências, 28:77-94

Saboia L.A. 1979 . Os greenstone belts de Crixás e Goiás - GO. Boletin de Geociências do Centro-Oeste, 9:44-72

Sawatzky D.L. \& Lee K. 1974. New use of shadow enhancement. In: F. SHAHROKRI (ed.) Remote Sensing of Earth Resources, Tullahoma, Tennessee, 5:1-18.

Sor PC M. Csordas S.M 1981. Análise Morfoestrutural Regional com Imagens de RADAR e LANDSAT na Bacia do Paraná. In: SBG, Simpósio Regional de Geologia, 3. Curitiba, Anais, 5-23.

Veneziani P. 1987. Análise de Movimentos da Tectônica Rúptil e Rúptil-Dúctil Arrovés de Interpretaçáo de Produtos de Sensores Remotos na Região do Espinhaço Meridi onal (MG): Uma Correlaçăo crom Processisos Evolutivos. Instituto de Geociências Universidade de São Paulo, São Paulo, Tese de Doutoramento.

Manuscrito A-1111

Recebido em 2 de agosto de 1999 Revisão dos autores em 1e agosto de 2000 Revisão aceita em 15 de agosto de 2000 